\title{
Spawanie złączy doczołowych jednorodnych ze stali Super 304H
}

\author{
Experience in welding of similar butt joint made \\ of Super $304 \mathrm{H}$ steel
}

\section{Streszczenie}

Przedstawiono zagadnienia dotyczące spawalności połączeń jednorodnych ze stali austenitycznej Super $304 \mathrm{H}$. Ponadto przeprowadzono badania oraz omówiono wyniki badań wykonanych złączy spawanych zgodnie z przewidzianym zakresem PN-EN 15614.

Słowa kluczowe: spawanie; spawalność; stale dla energetyki

\begin{abstract}
The paper presents experience in welding of similar butt joint made of Super $304 \mathrm{H}$ steel.In addition,studiem were carried out and discusses tere sults of butt joint according to the PN-EN 15614.
\end{abstract}

Keywords: welding; steels for energy industry

\section{Wstęp}

Zapotrzebowanie na energię elektryczną rośnie w Polsce z każdym rokiem w związku z rozwojem różnych gałęzi przemysłu. Wytwarzana energia elektryczna oparta jest na węglu kamiennym i brunatnym. Spalany węgiel w kotłach energetycznych powoduje emisję znacznych ilości szkodliwych gazów w postaci dwutlenku węgla $\left(\mathrm{CO}_{2}\right)$, dwutlenku siarki $\left(\mathrm{SO}_{2}\right)$, tlenków azotu $\left(\mathrm{NO}_{\mathrm{xw}}\right)$ oraz różnego rodzaju pyłów. Dyrektywa Parlamentu Europejskiego i Rady 2001/80/WE z 23 października 2001r. w sprawie „Ograniczenia emisji niektórych źródeł zanieczyszczeń do powietrza z dużych źródeł spalania paliw" ustala graniczne wartości dopuszczalne dla tych zanieczyszczeń $[1,2]$. Aby sprostać tym wymaganiom należy podjąć inwestycje w zakresie rekonstrukcji i modernizacji starych elektrowni jak również w budowę nowych obiektów o wysokiej sprawności. Dlatego w przemyśle energetycznym prowadzi się szereg badań w obecnych czasach dotyczących poprawy efektywności kotłów parowych. Poprawa efektywności wiąże się z zastosowaniem odpowiednich stali, które przez najdłuższy okres eksploatacji urządzeń energetycznych pracujących w wysokich temperaturach zachowają odpowiednie własności mechaniczne. Jakość produkowanych elementów konstrukcyjnych kotła zależy od czynników związanych zarówno z materiałem jak i technologią spawania i gięcia rur. Na elementy ciśnieniowe kotłów o nadkrytycznych parametrach pary są stosowane oraz rekomendowane stale TP347, HR3C, Sanicro 25 oraz stal typu Super 304H. Stal Super $304 \mathrm{H}$ należy do grupy stali o strukturze austenitycznej, które charakteryzuje się wysoką odpornością na korozję, odpornością na utlenianie-żaroodpornością oraz żarowytrzymałością w szerokim zakresie temperatur $[3,6]$.

\section{Opis przedmiotu badań}

Celem badań jest określenie spawalności złączy jednorodnych wykonanych ze stali Super $304 \mathrm{H}$.

Zakres badań obejmuje:

a) Wykonanie złączy jednorodnych ze stali Super $304 \mathrm{H}$ przy użyciu metody TIG w pozycji PF. Połączenia jednorodne zostały wykonane z rury o średnicy $\emptyset 54 \mathrm{~mm}$ i grubości ścianki $5 \mathrm{~mm}$ z wykorzystaniem materiałów dodatkowych firmy Bohler Thermanit H Cu (oznaczenie spoin S1, S2), ESAB OK. Tigrod 308H (oznaczanie spoin S3, S4), Lincoln TIG ER 308H (oznaczenie spoin S4, S6).

b) Przeprowadzenie badań nieniszczących i niszczących zgodnie z PN-EN ISO 15614-1 [7].

Tablica I. Skład chemiczny stali Super $304 \mathrm{H}$, \%mas.

Table I. Chemicalcomposition of Super $304 \mathrm{H}$ steel, \% mass.

\begin{tabular}{|c|c|c|c|c|c|c|c|c|c|}
\hline $\mathbf{C}$ & $\mathbf{S i}$ & $\mathbf{M n}$ & $\mathbf{P}$ & $\mathbf{S}$ & $\mathbf{C r}$ & $\mathbf{N i}$ & Mo & $\mathbf{C u}$ & $\mathbf{N b}$ \\
\hline 0,08 & 0,38 & 0,25 & 0,036 & 0,022 & 18,34 & 10,97 & 0,30 & 2,65 & 0,28 \\
\hline
\end{tabular}

Mgr inż. Maciej Gątarek (IWE) - PGE Górnictwo i Energetyka Konwencjonalna SA Oddział Elektrownia Bełchatów, Rogowiec; dr hab. inż. Jacek Słania, prof. IS; mgr inż. Łukasz Rawicki - Instytut Spawalnictwa w Gliwicach; dr hab.inż. Grzegorz Golański, prof. PCz - Instytut Inżynierii Materiałowej Politechnika Częstochowska; dr inż. Ryszard Krawczyk - Instytut Technologii Mechanicznych Politechnika Częstochowska; mgr inż. Paweł Urbańczyk - Urząd Dozoru Technicznego.

Autor korespondencyjny/Corresponding author: gatarekmaciej@gmail.com 


\section{Skład chemiczny materiału rodzimego}

Skład chemiczny materiału rodzimego, stali Super $304 \mathrm{H}$ określono za pomocą spektrometru iskrowego SpectroLab K2. Uzyskane wyniki będące średnią z trzech pomiarów zestawiono w tablicy I.

\section{Wyniki statycznej próby rozciągania}

Statyczną próbę rozciągania przeprowadzono za pomocą maszyny wytrzymałościowej Roel. Zwick Z100 stosując próbki płaskie z główkami w celu określenia wytrzymałości na rozciąganie $R_{m}$ oraz sprawdzenia zgodności z wymaganą minimalną wartość $\mathrm{R}_{\mathrm{m}}$ dla materiału rodzimego, która wynosi $590 \mathrm{MPa}$ dla stali Super 304H wg ASTM. Wyniki przeprowadzonych badań przedstawiono na rysunku 1 . Wszystkie rozciągane próbki uległy zerwaniu w spoinie.

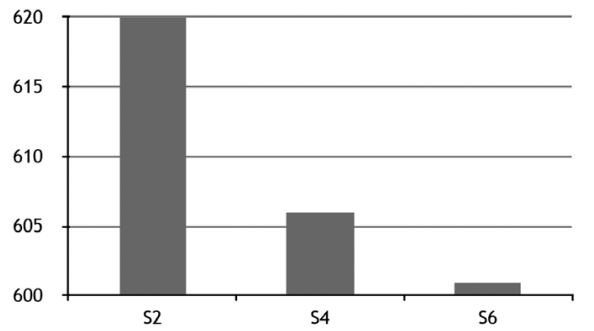

Wartość średnia Rm, MPa

Rys. 1. Wyniki statycznej próby rozciągania

Fig. 1. Tensile strength results

\section{Wyniki próby udarności złącza spawanego}

Próbę udarności przeprowadzono na niestandardowych próbkach o pomniejszonej do 2,5 mm szerokości z naciętym karbem typu „v". Badania przeprowadzono na młocie wahadłowym Charpy'ego o początkowej energii łamania wynoszącego 300J.

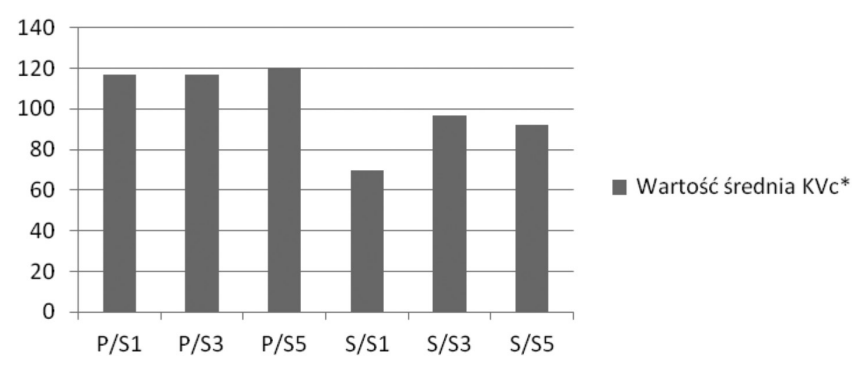

* - wartość średnia udarności obliczona z zależności $\mathrm{KV}_{\mathrm{c}}=\left(10 \times \mathrm{KV}_{\mathrm{p}}\right) / \mathrm{w} ; \mathrm{KV}_{\mathrm{p}}$ - wartość udarności uzyskana na próbce niestandardowej; J, w - szerokość próbki niestandardowej; mm (PN-EN 10216-2) [6];

Rys. 2. Wyniki próby udarności złącza spawanego

Fig. 2. Impact test results

\section{Wyniki próby zginania}

Próbę zginania lica i grani spoin wykonano zgodnie z PN-EN ISO 5173 [8]. Kryterium próby jest uzyskanie kąta gięcia 180, bez wystąpienia pęknięć na rozciąganej powierzchni. Przeprowadzone badania spełniają wymagania PN-EN 15614-1. Wyniki badań zostały przedstawione na rysunkach od 3 do 8 .

\section{Rozkład twardości na przekroju złącza}

Pomiar twardości wykonano metoda Vickersa stosując obciążenia wgłębnika wynoszące 10 kG $(98,1 \mathrm{~N})$. Pomiar

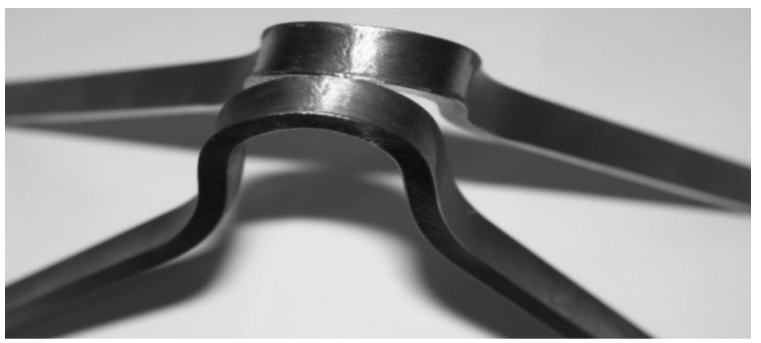

Rys. 3. Wynik prób zginania spoiny $\mathrm{S} 2$ od strony grani Fig. 3. Bending test results butt weld S2 root weld

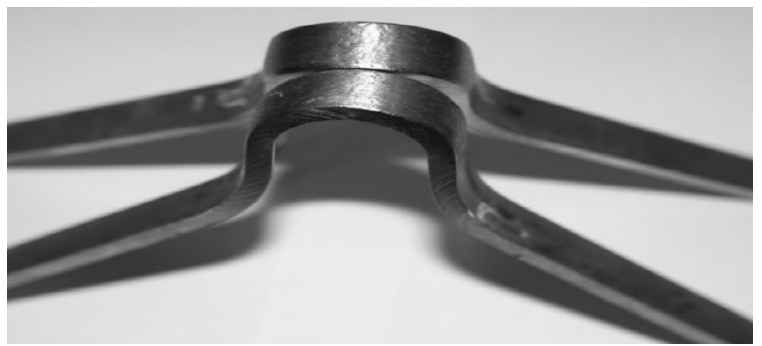

Rys. 4. Wynik prób zginania spoiny S2 od strony lica Fig. 4. Bending test results butt weld $S 2$ face weld

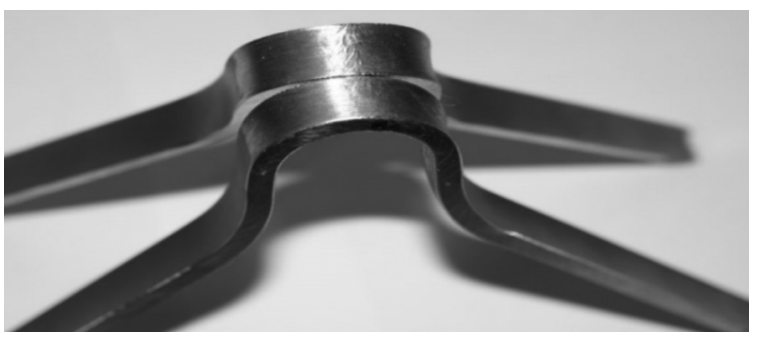

Rys. 5. Wynik próby zginania spoiny $\mathrm{S} 4$ od strony grani Fig. 5. Bending test results butt weld S4 root weld

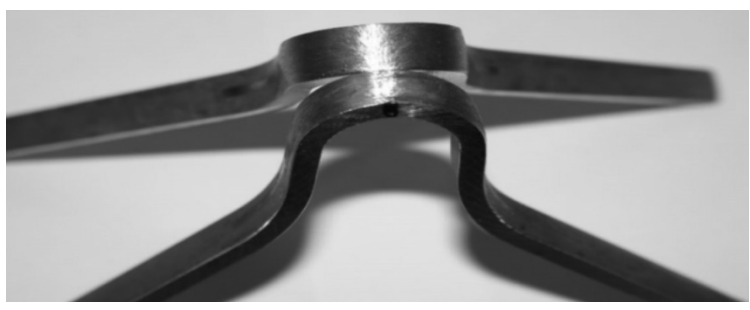

Rys. 6. Wynik prób zginania spoiny S4 od strony lica Fig. 6. Bending test results butt weld S4 face weld

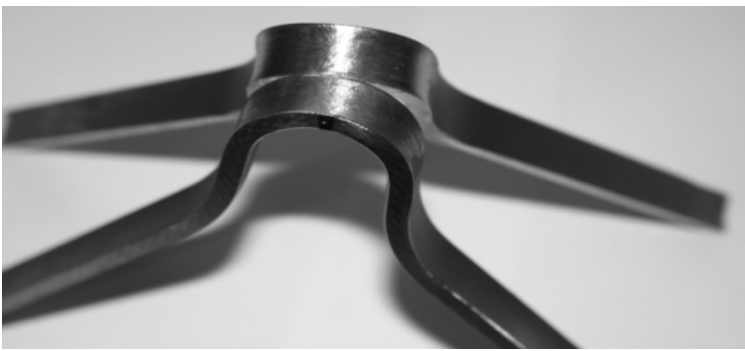

Rys. 7. Wynik próby zginania spoiny S6 od strony grani Fig. 7. Bending test results butt weld S6 rootweld

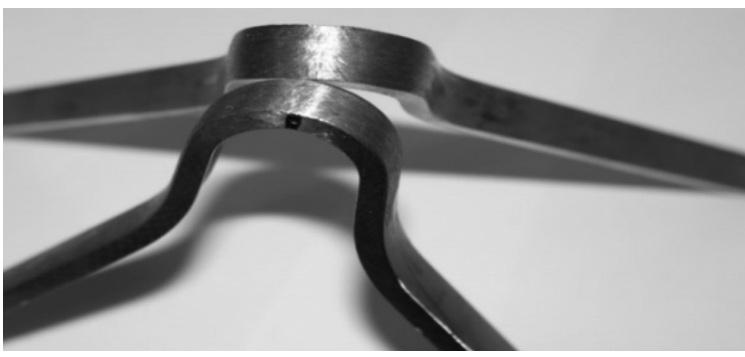

Rys. 8. Wynik próby zginania spoiny $\mathrm{S} 6$ od strony lica Fig. 8. Bending test results butt weld $S 6$ face weld 
twardości wykonano za pomocą twardościomierza Future - Tech FV-700. Wyniki pomiarów twardości na przekroju złącza spawanego dla poszczególnych próbek przedstawiono na rysunkach $9 \div 11$.

\section{Wyniki badań makroskopowych złączy spawanych}

Badania przeprowadzono zgodnie z PN-EN 1321 [9]. Na rysunkach $12 \div 4$ przedstawiono wyniki badań makroskopowych w formie zdjęć makroskopowych złączy jednorodnych S5, S3 i S1.

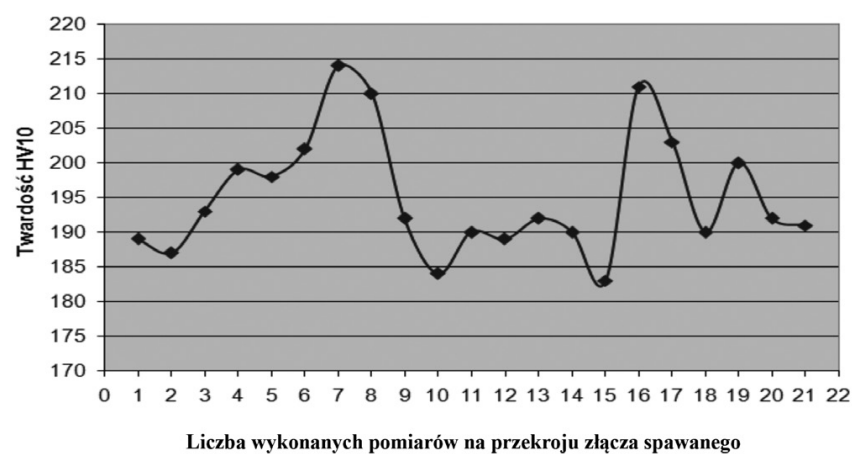

Rys. 9. Pomiar twardości na przekroju złącza S1

Fig. 9. Hardnes test butt weld S1

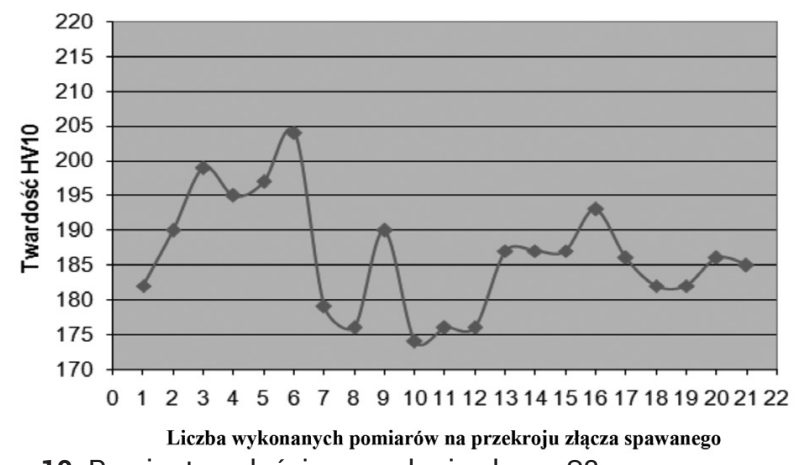

Rys. 10. Pomiar twardości na przekroju złącza S3

Fig. 10. Hardnes test buttweld S3

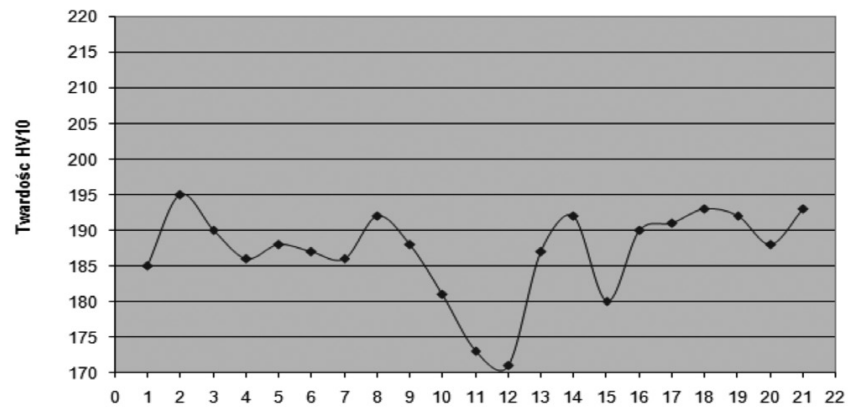

Liczba wykonanych pomiarów na przekroju zlącza spawanego

Rys. 11. Pomiar twardości na przekroju ze złącza S5

Fig. 11. Similar butt joint of Super $304 \mathrm{H}$ steel - S5

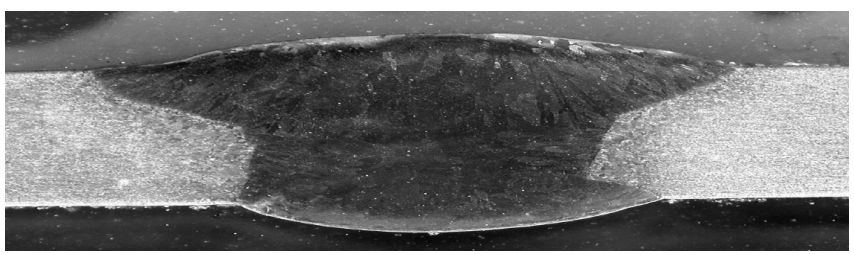

Rys. 12. Złącze jednorodne ze stal Super $304 \mathrm{H}-\mathrm{S} 5$

Fig. 12. Hardnes test butt weld S1

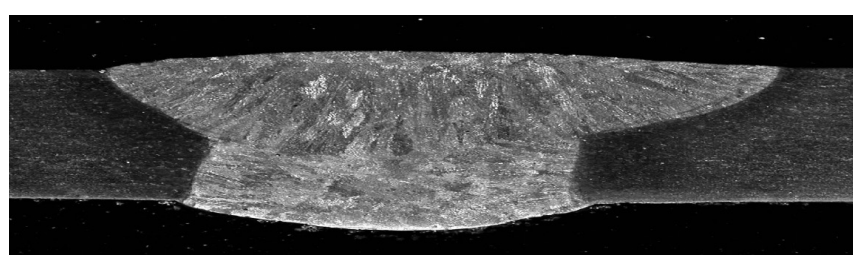

Rys. 13. Złącze jednorodne ze stali Super $304 \mathrm{H}-\mathrm{S} 3$

Fig. 13. Similar butt joint of Super $304 \mathrm{H}$ steel $-\mathrm{S} 3$

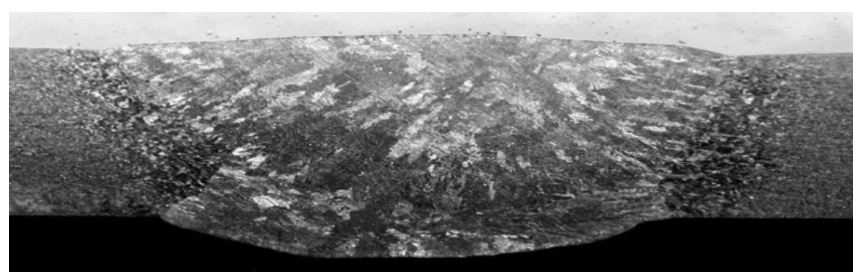

Rys. 14. Złącze jednorodne ze stali Super $304 \mathrm{H}-\mathrm{S} 1$

Fig. 14. Similar butt joint of Super $304 \mathrm{H}$ steel $-\mathrm{S} 1$

\section{Podsumowanie}

Celem przeprowadzonych badań było określenie przydatności do spawania stali austenitycznej Super 304H. Do przeprowadzenia badań wykonano połączenia jednorodne za pomocą metody TIG (141) przy użyciu austenitycznych materiałów dodatkowych: BohlerThermanit H Cu, ESAB OK. Tigrod 308H i Lincoln TIG ER 308H.Wykonane złącza w różnych konfiguracjach zostały poddane badaniom zgodnie z zakresem przewidzianym w PN-EN 15614-1 [7].

Przeprowadzone badania dotyczące statycznych prób rozciągania połączeń jednorodnych ze stali żarowytrzymałej Super 304H wykazały, że najwyższą wytrzymałość na rozciąganie posiadało złącze S2, gdzie średnia z trzech pomiarów wyniosła $620 \mathrm{MPa}$. Złącze S4 charakteryzowało się wartością $\mathrm{R}_{\mathrm{m}}=606 \mathrm{MPa}$, natomiast złącze S6 $\mathrm{R}_{\mathrm{m}}=601 \mathrm{MPa}$.

Próbę udarności przeprowadzono na niestandardowych próbkach o pomniejszonej do 2,5 mm szerokości z naciętym karbem typu "v" w spoinie oraz w SWC. Badania wykazały, że najwyższą wartość udarności w SWC uzyskała średnia z trzech pomiarów ze złącza S5, $\mathrm{KV}_{\mathrm{c}}=120 \mathrm{~J}$, a dla złączy S1 i S3 otrzymano zbliżoną wartość $\mathrm{KV}_{\mathrm{c}}=117 \mathrm{~J}$. Ponadto z przeprowadzonej próby udarności wykonanej na próbkach z karbem w spoinie najwyższą średnią wartość udarności trzech pomiarów otrzymano dla złącza S3, gdzie $\mathrm{KV}_{\mathrm{c}}=92 \mathrm{~J}$, natomiast najniższą wartość udarnościuzyskano dla złącza S1, gdzie $\mathrm{KV}_{\mathrm{c}}=72$.

W dalszej kolejności wykonano próbę zginania z rozciąganiem od strony lica i grani spoiny. Przeprowadzone badania nie wykazały rys i pęknięć na rozciąganych powierzchniach próbek.

Wykonane pomiary twardości nie są wymagane dla stali austenitycznych, wykonane zostały wyłączenie w celach poznawczych i wykazały, że twardość dla wszystkich analizowanych złączy w zależności od miejsca pomiaru wynosiła od 178 do 215 HV10.

Z przeprowadzonych badań makroskopowych dla wszystkich złączy uzyskano poziom jakości B wg PN-EN ISO 5817 [10]. 


\section{Literatura}

[1] Wstępna ocena wykonalności traktatu akcesyjnego w zakresie dyrektywy 2001/80/WE przez duże źródła spalania,data pobrania: 03.01.2015

[2] http://www.geoland.pl/dodatek/energia_xxxv/energoprojekt.html;

[3] Dyrektywa Nr2001/80/WE Parlamentu Europejskiego i Rady z dnia 23 października 2001 w sprawie ograniczenia emisji niektórych zanieczyszczeń do powietrza z dużych obiektów energetycznego spalania.

[4] Bolier Grade DMV 304HCu: Salzgitter Mannesmann Stainless Tubes, 2008

[5] Brózda J.:Stale austenityczne nowej generacji stosowane na urządzenia energetyki o parametrach nadkrytycznych i ich spawanie. Instytut Spawalnictwa, Gliwice,

[6] http://www.iaea.org/inis/collection/NCLCollectionStore/_Public/39/004/39004945.pdf; data pobrania 11.12.2015 r.
[7] Jachym R., Kwieciński K., Łomzik M., Urzynicok M.: Spawanie złączy doczołowych jedno- i różnoimiennych ze stali Tempaloy A-3. Przegląd Spawalnictwa 4/2012 str. 45-51.

[8] Zbroja P., Ziewiec A., Tasak E.: Skłonność do pęknięć gorących austenitycznej stali Super $304 \mathrm{H}$ przeznaczonej do pracy w podwyższonej temperaturze. Przegląd Spawalnictwa 1/2012, str. 10-14.

[9] PN-EN ISO 15614-1 - Kwalifikowanie technologii spawania część. Część I

[10] PN-EN ISO 5173 - Badania niszczące złączy spawanych metali - Próba rozciągania próbek wzdłużnych stopiwa złączy spawanych

[11] PN-EN 1321 - Badania niszczące spawanych złączy metali - Próba łamania

[12] PN-EN ISO 5817- Złącza spawane ze stali, niklu, tytanu i ich stopów (z wyjątkiem spawanych wiązką) - Poziomy jakości według niezgodności spawalniczych 